\title{
Microfiltration and ultra-high-pressure homogenization for extending the shelf-storage stability of UHT milk
}

D’Incecco P., Rosi V., Cabassi G., Hogenboom J.A., Pellegrino L.

Department of Food, Environmental and Nutritional Sciences (DeFENS), University of Milan, via Celoria 2, 20133, Milano, Italy

Consiglio per la ricerca in Agricoltura e l'analisi dell'economia agraria, CREA-ZA Via A. Lombardo 11, 26900 Lodi

\begin{abstract}
Fat separation, gelation or sedimentation of UHT milk during shelf-storage represent instability phenomena causing the product rejection by consumers. Stability of UHT milk is of increasing concern because access to emerging markets currently implies for this product to be stable during shipping and prolonged storage, up to 12 months. The role of microfiltration prior to UHT process in avoiding or retarding the gelation or sediment formation was studied by comparing microfiltered UHT milk to conventional UHT milk. A second trial was set up to study the effects of double ultrahigh pressure homogenization in delaying the cream rising and UHT milk homogenized once at lower pressure was taken as control. All milk samples were produced at industrial plant level. Milk packages were stored at $22{ }^{\circ} \mathrm{C}$, opened monthly for visually inspecting the presence of cream layer, gel or sediment and then analysed. Microfiltration markedly delayed the formation of both gel particles and sediment, with respect to the control, and slowed down the proteolysis in terms of accumulation of peptides although no correlation was observed between the two phenomena. The double homogenization, also evaluated at ultra-structural level, narrowed the fat globule distribution and the second one (400 MPa), performed downstream to the sterilization step, disrupted the fatprotein aggregates produced in the first one $(250 \mathrm{MPa})$. The adopted conditions avoided the
\end{abstract}


appearance of the cream layer in the UHT milk up to 18 months. This study contributes important knowledge for developing strategies to delay instability phenomena in UHT milk destined to extremely long shelf storage.

Keywords: Shelf-life, UHT milk, Gelation, Creaming, Proteolysis, Ultrastructure, Fat globule, Food waste.

\section{Introduction}

Ultra-high temperature (UHT) treated milk typically has a commercial shelf-life at ambient temperature lasting around 4-6 months. The possibility to store UHT milk with no refrigeration makes this commodity of increasing popularity in countries where consumption habits do not include liquid milk or no large productive units are present. Therefore, exporting UHT milk to these countries represents an interesting opportunity for dairy companies, with some obstacles related to the geographical distance, insufficient local network of distribution, and transport costs (Deeth \& Lewis, 2017). Furthermore, the availability of shelf-stable UHT milk may have beneficial impact on both food security policies for developing countries and strategies to limit food waste worldwide. Consequently, implementing the production of high-quality UHT milk with storage stability extended up to 10-12 months represents a challenging issue to get market access in new geographic areas, where consumption of drinking milk may potentially grow.

Fat separation, sedimentation or gelation phenomena represent the most common spoilage signs of UHT milk causing consumer complaint and product recall with high economic costs. Although mechanisms responsible for age gelation of UHT milk have been widely studied (Datta \& Deeth, 2003; Rauh, Sundgren, Bakman, Ipsen, Paulsson, Larsen, \& Hammershøj, 2014; Chavan, Chavan, Khedkar, \& Jana, 2011), agreement on a single mechanism has not been achieved. The literature 
agrees, however, that destabilisation of UHT milk is induced by the residual activity of proteolytic enzymes, although the quantitative aspects of this phenomenon are still far to be clarified (Baglinière et al., 2012; Stoeckel et al., 2016a). Plasmin, the major native protease, can withstand the UHT treatment and therefore contribute to casein degradation during subsequent milk storage (Rauh et al., 2014; Stoeckel et al., 2016b). Furthermore, heat-resistant proteases are produced by some bacteria, especially Pseudomonas spp., Bacillus spp., Serratia spp., that are currently considered as the main responsible of gelation phenomena in UHT milk (Datta \& Deeth, 2003; Lafarge et al., 2004; Machado et al., 2017). Bacteria belonging to these genera are capable to grow at low temperatures and thus may become the dominating species in raw milk since it is normally stored at $4-6{ }^{\circ} \mathrm{C}$ until processing. Formation of a sediment in the UHT milk package is less investigated (Stoeckel et al., 2016a). The amount of sediment increases faster in skim milk than in whole milk, where the presence of fat within protein aggregates reduces their density (Grewal, Chandrapala, Donkor, Apostolopoulos, \& Vasiljevic, 2017). The presence of a cream layer topping the UHT milk in the package also makes it unpleasant. Literature reports this to be the earliest appearing among the visually detectable signs of instability (Stoeckel et al., 2016a), although raising of fat globules is normally delayed by milk homogenization. Most of the studies focussed on decreasing the fat globules size in milk were conducted on pilot plants and lacked of a subsequent storage stability test (Hardham, Imison, \& French, 2000; Hayes, Fox, \& Kelly (2005).

No fully effective technological tools have been proposed allowing the storage stability of UHT milk to be increased significantly. Stoekel et al. (2016b) have recently reviewed the effectiveness of selected UHT processing conditions on the inactivation of proteases. However, the increase of process severity promotes unwanted chemical changes, such as the formation of lactulose or the Maillard reaction (Elliott, Datta, Amenu, \& Deeth, 2005; Cattaneo, Masotti, \& Pellegrino, 2008), which represent a heat damage to milk components bringing to the progressive 
browning of milk and development of flavour defects. Zhang et al., (2016) recently showed that the shelf-life of UHT milk can be increased up to four months by a preliminary microfiltration.

Among technologies intended to delay fat creaming in UHT milk, such as microfluidisation, ultrasonics, membrane emulsification, high speed mixing (Huppertz, 2011), relevant improvements were achieved with the last-generation homogenizers, due to the high pressures they may reach. In fact, while standard homogenization is carried out at an upstream pressure of 20-60 MPa, the highpressure homogenization $(\mathrm{HPH})$ reaches $200 \mathrm{MPa}$, and the ultra-high-pressure homogenization (UHPH) goes up to 400-600 MPa (Dumay et al., 2013; Schlender, Minke, Spiegel, \& Schuchmann, 2015).

Although many studies have investigated factors influencing the storage stability of UHT milk, to our knowledge there is no literature available on technological interventions designed to extend the shelf-life of UHT milk up to 12 months. Our study aimed to evaluate whether the stability of UHT milk can be significantly increased by introducing selected changes in the technological process. In particular, the effectiveness of the microfiltration of milk before the UHT treatment has been evaluated over a storage period up to 12 months with respect to a conventional UHT process conducted at more severe time/temperature conditions. The stability of milk was assessed by visually inspecting the occurrence of gelation, sedimentation or cream layer and evaluating the proteolysis extent by different approaches. Furthermore, the effect of a double homogenization with respect to a single process was studied in microfiltered UHT milk on storage by measuring the particle size distribution by means of laser light scattering, and evaluating the ultrastructure of fat globules by confocal laser scanning microscopy and electron microscopy. The single homogenization was performed before UHT treatment by HPH. For the double homogenization, this last was coupled with an UHPH process carried out after the UHT treatment. All milk processes were carried out at industrial plant level with the aim of both studying the phenomena occurring in 
commercial products when stored for an extremely long time and achieving information of technological interest to UHT milk manufacturers.

\section{Materials and Methods}

\subsection{Experimental design}

Two separate trials were designed to investigate the effect of two different processing methods applied in UHT milk production. All milk was processed by UHT indirect heating (tubular heat exchanger) in a commercial plant (Tetra-Pack, Lund, Sweden) and aseptically packaged in 1-L bricks. Process conditions adopted in the two trials are outlined in Suppl. Fig. 1. Trial 1 was intended to study the effect of a microfiltration $(1.4-\mu \mathrm{m}$ ceramic membrane) pre-treatment by comparing traditional UHT milk (UHT) to microfiltered UHT milk (MF-UHT). Full fat (3.5\% w/v), semi-skimmed $(1.5 \%)$ and skimmed $(0.5 \%)$ milks were produced from a single batch of raw milk with no replicates. A total of 180 packages were stored at $22 \pm 1{ }^{\circ} \mathrm{C}$ for up to 12 months and three packages were taken for stability evaluation and analysed in triplicate at each sampling time.

In Trial 2, the effect of double homogenization (model "Tetra Alex 400"®, Lund, Sweden) was investigated by comparing UHT milk homogenized by a single pass at 250MPa (HOM-1) to UHT milk submitted to an additional (downstream) homogenization at $400 \mathrm{MPa}$ (HOM-2) (Suppl. Fig. 1). Only full fat milks were produced from a single batch of raw milk with no replicates. Eighteen packages were considered, six packages were analysed one day after production, the others were stored at $22 \pm 1{ }^{\circ} \mathrm{C}$ and analysed after 12 or 18 months.

Based on the manufacturer data, both the batches of raw milk used for the two trials fulfilled the legal requirements (European Union, 2004) for the total plate counts $(18,000$ and $15,500 \mathrm{CFU} / \mathrm{mL}$ ) and somatic cells counts (175,000 and 162,000 cells/mL). 


\subsection{Visual assessment of milk stability}

Milk packages were carefully opened at the selected dates and visually evaluated for the presence of instability signs: cream layer, gel particles and sediment. Presence was considered as positive (+) when the parameter reached the level that would be detectable to consumers. In particular: (i) presence of a cream layer was considered as positive when it could be interrupted with a spatula; (ii) presence of gel particles visible to naked eye or complete gelling were assessed on pouring the milk in a beaker, and (iii) the sediment was assumed to be present when a white layer fully covering the bottom of the package remained after pouring the milk. Positivity for single indicators was assumed when it was observed in at least two out of the three inspected packages.

Milk pH was measured with a Crison Basic20 (Lainate, Italy) pH-meter at opening of each package.

\subsection{Milk heat-damage evaluation}

Levels of furosine (ISO, 2004) and lactulose (ISO, 2007) were determined in duplicate on the freshly manufactured milk samples of Trial 1, as indices of heat treatment severity. In addition, the level of soluble $\alpha$-lactalbumin (a-La) was determined by HPLC as beyond described and quantified using the response factor of an external standard of a-La (Sigma Aldrich, Milan, IT).

2.4 Proteolysis extent evaluation by high-performance liquid chromatography (HPLC), capillary zone electrophoresis (CZE) and ion-exchange chromatography (IEC)

The sample preparation for HPLC analysis of peptides was as follows. A 25-ml aliquot of milk was adjusted to $\mathrm{pH} 4.6$ using $2 \mathrm{~N} \mathrm{HCl}$. After centrifugation $\left(3000 \mathrm{~g}, 20 \mathrm{~min}\right.$ at $\left.10{ }^{\circ} \mathrm{C}\right)$ and filtration of the supernatant through a $0.22 \mu \mathrm{m}$ membrane filter (Millipore), the filtrate was analysed under the conditions described by Pellegrino, Rosi, D'Incecco, Stroppa, \& Hogenboom, (2015). The chromatographic separation was carried out using an Alliance HPLC system equipped with a 2996 diode array detector (Waters, Milford, MA, USA) operating at $205 \mathrm{~nm}$ and a PLRP-S column (250 
x 4.6 mm, $300 \AA$ pore size, $5 \mu \mathrm{m}$ particle size) (Polymer Laboratories Ltd, UK). Chromatographic data were recorded and processed using the Empower ${ }^{\mathrm{TM}}$ software (Waters). The total area of peptide peaks was considered.

The same filtrate used for the HPLC analysis was run by CZE to quantify the proteose peptones. A 1-ml aliquot of filtrate was added with $1 \mathrm{ml}$ of $10 \mathrm{M}$ urea buffer $(\mathrm{pH} 8.6)$ and kept at room temperature for $4 \mathrm{~h}$, then filtered through a $0.22 \mu \mathrm{m}$ membrane filter (Millipore). Run buffers were prepared according to Recio \& Olieman (1996). A Beckman P/ACE system MDQ equipment (Beckman Coulter, Fullerton, CA) with UV detection at $214 \mathrm{~nm}$ was adopted. A coated capillary column (DB-WAX, J \& W Agilent Technologies Inc., Santa Clara, CA) was cut manually and lowflame window burning was used to remove the polyimide coating. Effective column length was 500 $\mathrm{mm}$ and the slit opening was set at $100 \times 800 \mu \mathrm{m}$. The injection was carried out at the anode by pressure injection at 0.5 psi for $20 \mathrm{~s}$ and the separation was carried out at $45^{\circ} \mathrm{C}$ using a linear gradient from 0 to $30 \mathrm{kV}$ in $4 \mathrm{~min}$, followed by constant voltage at $30 \mathrm{kV}$ for $36 \mathrm{~min}$. Before each run, the capillary was counter flow flushed with the run buffer for $5 \mathrm{~min}$. Assignment of the peaks was done by spiking and corrected peak areas (calculated as peak area/migration time) were measured.

The free amino acid composition was analysed by IEC as described by Hogenboom, D'Incecco, Fuselli, \& Pellegrino, (2017). The same filtrate prepared for HPLC analyses was further adjusted to pH 2.2 using $2 \mathrm{~N} \mathrm{HCl}$ and filtered on $0.22 \mu \mathrm{m}$ membrane filter (Millipore). A Biochrom 30+ amino acid analyser (Erreci srl, Milano, Italy) was used with a post-column derivatization with ninhydrin (Erreci srl) and detection at 570 and $440 \mathrm{~nm}$. Quantification was done using four-level calibration curves.

2.5 Confocal Laser Scanning Microscopy (CLSM) and image analysis 
CLSM analyses were performed on UHT milks homogenized either once (HOM-1) or twice (HOM2) (Suppl. Fig. 1, Trial 2) to investigate the microstructure of fat globules. Samples were stained with Nile red (Sigma-Aldrich, St Louis, USA) to detect the triacylglycerol core of fat globules. The Nile red stock solution $(1 \mathrm{mg} / \mathrm{mL}$ ) was prepared in $80 \%$ v/v DMSO (Sigma-Aldrich, St Louise, USA) and kept protected from light until use. Direct staining was performed by adding $50 \mu \mathrm{L}$ Nile red stock solution to $450 \mu \mathrm{L}$ of milk. After 15 min of incubation at room temperature, samples were observed using an inverted CLSM from Leica Microsystem (Heidelberg, Germany). Nile red was excited at $488 \mathrm{~nm}$ using an argon laser and the emission filter was set at 520-590 nm. Maximum projections consist of 230 layers of 512 x 512 pixels images that are stacked together with separation between layers set at $0.30 \mu \mathrm{m}$.

Image analysis was performed using ImageJ software (Research Services Branch, National Institute of Health and Medicine, USA) on maximum projection of CLSM z-stack images. Nuclei counting plugin was used to count the number of fat globules in the CLSM images. Number of counted fat globules are the mean of three different measurements.

\subsection{Transmission Electron Microscopy (TEM)}

Ultrastructure of the milk samples submitted to different homogenization treatments, HOM-1 and HOM-2, as well as the control raw milk, was investigated adopting the conditions described by D'Incecco, Pellegrino, Hogenboom, Cocconcelli, \& Bassi, (2018). Briefly, a $0.5 \mathrm{~mL}$ aliquot of sample was mixed with $2 \mathrm{~mL}$ of low-temperature gelling agarose $(2 \% \mathrm{w} / \mathrm{v}$ in water, melted at 35 $40^{\circ} \mathrm{C}$ ) (VWR, Milan, Italy). The suspension was layered onto a microscope slide, allowed to set and then cut into $1 \mathrm{~mm}^{3}$ cubes. The cubes were fixed in fixative solution (glutaraldehyde $1 \%$, paraformaldehyde $4 \%$ in Na cacodylate buffer, w/v) (Agar Scientific, Stansted, UK) for $2 \mathrm{~h}$ at $4^{\circ} \mathrm{C}$, then washed with $0.1 \mathrm{M} \mathrm{Na}$ cacodylate buffer for $1 \mathrm{~h}$ and post-fixed in osmium tetroxide (EMS, Hatfield, USA) (1\% in water, w/v) for $2 \mathrm{~h}$. Samples were dehydrated in a series of ethanol 
solutions, then embedded in Spurr resin (EMS, Hatfield, USA), and finally cured at $60^{\circ} \mathrm{C}$ for $24 \mathrm{~h}$. Ultrathin (50-60 nm thick) sections, were cut and stained with uranyl acetate and lead citrate (EMS, Hatfield, USA), both $0.2 \%$ in water (w/v). Sections were examined with a Philips E208 transmission electron microscope (Philips Technology, Aachen, Germany).

\subsection{Fat globule size distribution}

Fat globule particle size distribution (PSD) analysis was performed by light scattering analysis (LSA) using a Malvern Mastersizer 2000 (Malvern Instruments, UK) equipped with a laser source at $633 \mathrm{~nm}$. Parameters for the PSD calculation according to Mie theory were as described by Michalski, Briard, \& Michel, (2001): water was used as dilution medium (1:800) in order to avoid multiple scattering phenomena and excessive obscuration due to casein micelles; refractive indexes were set at 1.33 for water and 1.458 for milk fat; the absorption coefficient was measured on liquid fat and was set at $0.5^{*} 10^{-5}$. Milk samples were also diluted in presence of SDS (3 g/L) as reported by Thiebaud, Dumay, Picart, Guiraud, \& Cheftel (2003). In order to avoid fat crystallization, measurements were carried out at $40{ }^{\circ} \mathrm{C} \pm 1{ }^{\circ} \mathrm{C}$. The mean values of the particle size measured in micron were expressed as $\mathrm{D}_{4.3}$ (volume weighted mean) and $\mathrm{D}_{3.2}$ (surface weighted mean) values. Size dispersion was evaluated directly by the software of the instrument, using the span index (SI), according to the formula, $100 *\left(D_{90}-D_{10) /} D_{50}\right.$, where $D_{10}, D_{50}, D_{90}$ represent the size of the sample lying below 10, 50 and $90 \%$ of volume of the entire distribution, respectively.

\subsection{Statistical analysis}

Once the hypotheses of normality and homoscedasticity were accepted, data of small peptides and free amino acid in milk samples of Trial 1 after 12 months storage were analysed by two-way analysis of variance (ANOVA) for significant differences with respect to both type of process (UHT, MF-UHT) and fat level (whole, semi-skimmed, skimmed), and possible interactions between 
the factors. Differences among means of samples with different fat content were checked using the Ducan test. Data regarding fat globule number (image analysis) or $\mathrm{D}_{4.3}$ and $\mathrm{D}_{3.2}$ values (LSA) from Trial 2 were analysed by Student's $t$-test. Statistical treatment of data was performed by means of SPSS Win 12.0 program (SPSS Inc., Chicago, IL) and a $P<0.05$ was assumed as the significance limit.

\section{Results and discussion}

\subsection{Effect of microfiltration on storage stability of UHT milk}

Microfiltration of preliminarily skimmed milk allows mechanical removal of somatic cells, bacterial

cells and spores together with the associated enzymes (Fernández García, Álvarez Blanco, \& Riera Rodríguez, (2013). Removal of somatic cells has also an indirect effect on plasmin activity due to the concomitantly removal of the plasmin system activators associated to them (Verdi \& Barbano, 1991). With this aim, in Trial 1 we have applied the microfiltration as a pre-treatment in the indirect UHT milk (MF-UHT) processing. Furthermore, the UHT process was conducted at milder heating conditions $\left(137^{\circ} \mathrm{C} / 3 \mathrm{~s}\right)$ than in the conventional UHT process $\left(147^{\circ} \mathrm{C} / 5 \mathrm{~s}\right)$ taken as a control, in view of assessing the possibility of limiting the heat damage as an additional goal (Suppl. Fig. 1). The actual heat damage in the two types of milk was evaluated in terms of furosine, lactulose and soluble (undenatured) a-La levels measured immediately after processing (Table 1). The levels of these markers in the control UHT milk were comparable to levels reported for commercial indirect UHT milk, regardless the fat content, whereas levels in the MF-UHT were significantly $(\mathrm{P}<0.05)$ different from the control and close to those typically observed in direct UHT milk (Elliott et al., 2005; Cattaneo et al., 2008; Lorenzen, Clawin-Rädecker, Einhoff, Hammer, Hartmann, Hoffmann, ... \& Devrese, 2011). 
The destabilization of milk was monitored by visually evaluating the presence of a cream layer, a sediment, or gel particles in the milk packages at the selected sampling times, without quantification purpose. Differences among treatments were observed starting from four months of storage, which corresponds to the usual shelf-life of conventional UHT milk (Table 2).

The cream layer appeared at four months of storage in both whole and semi-skimmed MF-UHT milk and two months later in the corresponding UHT milk samples. No fat separation occurred in the skimmed milk samples during the whole storage period. The appearance of a thin undispersible sediment on the bottom of the package was delayed by 4-5 months in both whole and semiskimmed MF-UHT milks and by two months in the skimmed milk, with respect to the corresponding UHT milk samples. However, the most relevant differences among treatments regarded the storage time at which milk gelation occurred. In fact, gel particles were observed starting from eight, ten and six months in whole, semi-skimmed and skimmed UHT milk respectively, whereas their presence in MF-UHT milks was only observed in the skimmed type after 11 months of storage. Complete milk gelation only occurred in one out three packages of skimmed UHT milk at 11 months storage. Over the studied period, drops of $\mathrm{pH}$ value up to 0.15 and 0.25 units were observed for MF-UHT and UHT milks respectively (not shown), in agreement with the lower heat load applied to the former. In fact, a slow decrease of $\mathrm{pH}$ value in UHT milk during storage has been attributed to the progress of the Maillard reaction that represents the most important chemical reaction upon prolonged storage (Elliot, et al., 2005). Overall, these data indicate that the prior microfiltration had a positive effect on increasing the shelf stability of UHT milk, though the severity of heating conditions was concomitantly reduced with the advantage of a lower heat damage to milk constituents. Microfiltration had no efficacy, however, in retarding the formation of the cream layer that was even slightly anticipated. This aspect was specifically addressed in the second part (Trial 2) of this study. 
The casein proteolysis taking place during milk storage was investigated since it can influence the capability of casein micelles to form a gel or a sediment (Baglinière et al., 2012; Deeth \& Lewis, 2017). In fact, contrary to whey proteins, which are remarkably stable to proteolysis (Chavan et al., 2011), caseins in UHT milk may undergo degradation due to residual heat-stable proteases. Plasmin preferentially splits $\beta$-casein into $\gamma$-caseins and proteose peptones (PPs) (Datta \& Deeth, 2003). Therefore, PPs content was adopted as a suitable analytical index of plasmin activity in milk (De Noni, Pellegrino, Cattaneo, \& Resmini, 2007; Cattaneo, Stuknyté, Pellegrino, \& De Noni, 2014). When storage time of UHT milk was over two-three months, however, the shape of PPs peaks progressively broadened in the HPLC chromatograms (not shown), making their quantitative evaluation unreliable. The same difficulty was reported by other authors for whey proteins (Recio, de Frutos, Olano, \& Ramos, 1996; Elliot et al., 2005; Pellegrino, Cattaneo, \& De Noni, 2011) and for casein fractions (Gaucher, Mollé, Gagnaire, \& Gaucheron, 2008) in the HPLC patterns of long stored UHT milks as a consequence of the progressive protein glycosylation. Recio et al. (1996) proposed CZE as an alternative analytical approach less prone to protein glycosylation interference. However, the analytical conditions adopted by these authors make PPs peaks elute very close to the main whey proteins and thus still difficult to quantify. In contrast, under the CZE conditions proposed in this study, PPs eluted as a series of well-shaped peaks, free of interferences in all of the samples, as shown in Fig. 1 for the semi-skimmed milks at 0,6 and 12 months of storage.

PPs peaks decreased progressively in both types of milk during storage. This decrease could result from two possible ways: i) higher rate of PPs degradation than their rate of formation by plasmin residual activity or reactivated plasmin; ii) exclusive degradation by heat resistant bacterial proteinases released in the milk before heat treatment. However, in spite of the low bacterial count of the two batches of raw milk, the latter hypothesis could be the more likely. In fact, indirect UHT treatment of milk is reported to irreversibly inactivate plasmin (Kelly \& Foley, 1997; Chavan et al., 2011; Stoekel et al., 2016b) and other indigenous or somatic-cell-associated proteolytic enzymes 
(O’Mahony, Fox \& Kelly, 2013). Moreover, removal of somatic cells prevents plasmin activity in MF-UHT milk (Elwell \& Barbano, 2006; Zhang et al., 2016).

Time course accumulation of small peptides (SPs) was monitored by HPLC analysis of the $\mathrm{pH}$ 4.6soluble fraction of milk over the storage period considered in this study. The patterns of SPs eluting early (4-11 $\mathrm{min})$ in the chromatogram were easily identified under the analytical conditions previously proposed (Pellegrino et al., 2015) since, contrary to whey proteins and PPs, the peak shape was not modified by glycosylation (not shown). Several authors agree on the assignment of peaks eluting in the first region of the HPLC chromatogram of milk soluble fraction to SPs produced by bacterial proteolysis (López-Fandiño, Olano, San José, \& Ramos, 1993; Morales \& Perez, 1998; Datta \& Deeth, 2003). Overall, the SPs fraction progressively increased but increase was slower in MF-UHT milk (Fig. 2). After 12 months of storage, in MF-UHT milk the increase was $21 \%$ in whole milk and $39 \%$ in skimmed milk, whereas in UHT milk SPs had increased by $68 \%$ in the whole milk and by $95 \%$ in skimmed milk. The differences in percent increase were significant $(\mathrm{P}<0.05)$ between UHT and MF-UHT milk as well as between skimmed and semi skimmed or whole milk. Considering that the more severe the heat treatment the more intense the denaturation of whey proteins and their binding to casein micelles (Hillbrick et al., 1999), one would have expected a reduced accessibility of proteases to micelles, thus a lower proteolysis extent, in conventional UHT milk. In fact, this situation was observed in the first months of storage, then it inverted. The increased SPs accumulation in conventional UHT milk might have been due to the slow release of intracellular proteases consequent to lysis of bacterial cells that, in contrast, were removed from MF-UHT milk. Slow spontaneous reactivation of proteolytic enzymes might have occurred during UHT milk storage. However, our data failed to show the lack of any proteolytic activity due to milk microfiltration, confirming the findings of Zhang et al. (2016). These authors found microfiltration to significantly slow down, but not prevent, accumulation of non-casein nitrogen in UHT milk stored at $37^{\circ} \mathrm{C}$ up to four months. 
Our data of SPs accumulation showed that the proteolytic activity proceeds in either milk types over an extremely long time period, longer than ever inspected before, and that the delaying effect obtained by adopting the microfiltration becomes progressively more evident. Such a long-term enzyme activity could be facilitated by the dissociation of caseins (particularly k-casein) from micelles on heating (Hillbrick et al., 1999). Gaucher et al., (2008) suggested that a long storage of UHT milk could induce a non-enzymatic proteolysis leading to the release of specific peptides. Furthermore, late proteolysis might also be due to proteases having properties, such as an extremely high thermal stability or capability of reactivating, which are poorly substantiated in the literature (Deeth \& Lewis, 2017). Therefore, additional data are needed to support these hypotheses.

In all samples, the final levels of SPs were negatively correlated with the fat content of the milk, likely because of a reduced accessibility of casein micelles to proteases when adsorbed onto fat globule surface in homogenized milk (Walstra, Wouters, \& Guerts, 2006).

Finally, we have determined the content of free amino acids (FAA) in the milk samples stored for 12 months. Total FAA contents were in the range $85-100 \mathrm{mg} / \mathrm{L}$ and $88-91 \mathrm{mg} / \mathrm{L}$ in UHT and MFUHT milks respectively and were not significantly different. These levels were comparable to those observed in raw milk (Pellegrino et al., 2015), indicating that the proteolysis in UHT milk mostly promoted accumulation of SPs. This observation is consistent with the requirement of higher proteolytic specificities to split FAA from peptides that probably are no longer present in UHT milk. Similarly, Zhang et al. (2016) found no increase in non-protein nitrogen (NPN) in both microfiltered and non-microfiltered UHT milks over a 4-month storage. Other authors failed to detect any increase in NPN fraction in conventional UHT milk during storage unless conducted at very high temperatures (Gaucher et al., 2008; Baglinière et al., 2012). 


\subsection{Effect of homogenization on the storage stability of UHT milk}

Fat globule size was the parameter, according to Stoke's law, we focussed on in "Trial 2". To delay creaming of fat globules during long shelf-storage of UHT milk, a second homogenization (HOM2) through a downstream double stage aseptic homogenizer at ultra-high-pressure (UHP) of 400 $\mathrm{MPa}$ and inlet $\mathrm{T}$ of $50-55^{\circ} \mathrm{C}$ was experimented. A single homogenization was used for the control UHT milk (HOM-1). After 12 months of storage at room temperature, a thick layer of fat had surfaced on top of all the HOM-1 samples (Suppl. Fig. 2), making the product unacceptable for consumers. Differently, the three HOM-2 samples were still physically stable since no creaming of fat occurred and the same situation was observed in three packages of HOM-2 milk stored up to 18 months.

Light scattering analysis (LSA) was performed on all milk samples, as long as they did not destabilize during the 12-month storage period, and the volume-weighted mean of fat globules was considered, because this descriptor of particle size distribution (PSD) is more sensitive to the presence of small amounts of large globules. As expected, the averages $D_{4.3}$ and $D_{3.2}$ of the fat globules were significantly $(\mathrm{P}<0.05)$ smaller and globule size distributions were narrowed in the homogenized samples than in the untreated raw whole milk (Fig. 3). In particular, LSA of freshly produced milk samples showed a larger size of the fat globules in the HOM-1 than in HOM-2. The average $\mathrm{D}_{4.3}$ of the fat globules significantly $(\mathrm{P}<0.05)$ decreased from $0.44 \pm 0.03$ in the HOM-1 sample to $0.34 \pm 0.002$ in the HOM-2 sample. Likewise, the $\mathrm{D}_{3.2}$ significantly $(\mathrm{P}<0.05)$ decreased from $0.31 \pm 0.05$ in HOM-1 to $0.28 \pm 0.001$ in HOM-2. In fact, the volume of fat represented by globules having a diameter in the range $0.16-0.63 \mu \mathrm{m}$ was smaller in HOM-1, with respect to HOM-2, and volume of globules in the range $0.63-1.90 \mu \mathrm{m}$ was bigger. A shoulder observed in the distribution for HOM-1, and corresponding to globules 2-4 $\mu \mathrm{m}$ in diameter, lacked in HOM-2. The fat globule size distribution after 12 and 18 months of storage was analysed only in HOM-2 since in HOM-1 packages a thick layer of cream was already present at the end of 12 months (Fig. 
3). The $\mathrm{D}_{4.3}$ value of the HOM-2 sample didn't change significantly $(\mathrm{P}<0.05)$ from the beginning of the storage up to 18 months (Fig. 3), consistently with the absence of fat separation.

The addition of SDS to samples before size measurements did not change the differences we observed among samples nor the size distribution, supporting the reliability of the sample preparation we carried out. Picart, Thiebaud, René, Guiraud, Cheftel, \& Dumay (2006) also reported the lack of effect of SDS addition.

The CLSM images of both HOM-1 and HOM-2 UHT milk samples were taken at the beginning of the storage (Fig. 4). Larger fat globules were observed in HOM-1 (Fig. 4a, arrows) and fat globules around $3 \mu \mathrm{m}$ in size were observed in HOM-1 but not in HOM-2, consistently with LSA results. Contrary to HOM-1, only single fat globules were observed in HOM-2 where the second homogenization had increased the number of fat globules significantly $(\mathrm{P}<0.05)$. Fat globules counted by image analysis were 2,200 in HOM-2 and 1,100 in the HOM-1.

An extremely thin veil of cream was visible on top of HOM-2 milk stored for 18 months (not shown). CLSM analysis showed it to contain some small structures of partial coalesced fat globules (Fig. 5c, arrows) that were absent in the rest of milk (Fig. 5a) where globules looked not different from those analysed at the beginning of the storage.

The presence of interactions between fat globules and casein micelles was investigated using TEM analysis. Free casein micelles predominated in a raw milk taken as a reference (Fig. 6a). Differently, casein micelles shared among clusters of fat globules were observed in the HOM-1 sample (Fig. 6b), consistently with CLSM images. Micelles were involved in large clusters, often including more fat globules, even very small, that were mostly undamaged. A remarkably different ultrastructure characterized the HOM-2 sample (Fig. 6c), where the clusters formed as an effect of the first homogenization and the subsequent heat treatment were broken up into numerous small fragments originating from both fat globules and casein micelles. Fat globules looked severely damaged and tracts of milk fat globule membrane (MFGM) were often lacking. This picture makes 
the relevant increase in fat stability achieved in HOM-2 clearly understandable. To our knowledge no ultrastructural studies are available on the effects of UHPH on milk components.

Our results showed that repeating the homogenization treatment by a downstream UHPH operating at $400 \mathrm{MPa}$ may successfully delay both creaming and fat coalescence in UHT milk. In fact, HOM2 milk proved to be fully stable up to 12 months and showed an acceptable stability even after 18 months. On the contrary, a thick cream layer was present in the packages of HOM-1 after 12 months of storage, but likely fat creaming started earlier, as it was observed in Trial 1 . The second homogenization significantly decreased the mean fat globule diameter $\mathrm{D}_{4.3}$. However, it did not further reduce the size of the smallest globules but rather increased their number at the expense of larger globules. Thiebaud et al., (2003) reported a double homogenization at $150 \mathrm{MPa}$ to be more effective in reducing fat globule size than a single homogenization carried out at higher pressure of $300 \mathrm{MPa}$. However, considering that higher pressures of homogenization resulted more effective in decreasing the fat globule size (Hussain, Truong, Bansal, \& Bhandari, 2017; Long, Zhao, Zhao, Yang, \& Liu, 2012), our strategy was to raise the pressure of the second homogenizer up to 400 MPa. The $\mathrm{D}_{4.3}$ values we obtained at 250 or $400 \mathrm{MPa}$ were slightly higher than those obtained by Picart, et al., (2006) at $200 \mathrm{MPa}$ and $300 \mathrm{MPa}$. However, conditions in the two studies were not fully comparable in terms of $\mathrm{D}_{4.3}$ value of the raw milk and applied heat treatment. Instead, the results we obtained at $250 \mathrm{MPa}$ were similar to those of Hayes \& Kelly (2003) and Hayes et al. (2005). No literature is available about the effect of homogenization carried out around $400 \mathrm{MPa}$ on increasing the fat stability during storage of UHT milk, since studies were rather focussed on the consequent microbial and enzymes inactivation (Picart, et al., 2006).

Also the positioning of the homogenizer, either upstream or downstream the UHT treatment, influences the storage stability of UHT milk. Hardham et al. (2000) showed that dowstream homogenization was able to delay the formation of a cream layer in UHT milk from two to four months of storage. At the same time, a low inlet homogenization pressure (20 MPa) was unable to 
provide a longer storage stability. Like us, these authors showed a greater amount of proteins incorporated in the MFGM when the homogenization treatment is applied before the UHT process.

\subsection{Conclusions}

To our knowledge, this study is the first one attempting to investigate the effectiveness of microfiltration and double homogenization in UHT milk processing on shelf stability over a 12month storage period. Our results indicate that no direct correlation exists between the extent of proteolysis and the appearance of gelation or sedimentation. Preliminary microfiltration of milk delayed both these phenomena significantly, compared to the control milk, although the subsequent UHT treatment was conducted at milder heating conditions. The presence of fat may either favor or oppose protein interactions, however a clear negative effect of fat level on the release of SPs during storage was shown. Fat creaming in UHT milk was successfully prevented until after 18 months storage by double homogenization performed at $250 \mathrm{MPa}$ and $400 \mathrm{MPa}$ as pre- and post-UHT treatment respectively. Overall, the combination of microfiltration and UHPH to a conventional UHT milk was an effective strategy to guarantee the shelf storage stability of UHT milk at room temperature up to 12 months without implying an increase in the severity of the sterilization conditions. This study has brought out a new view of technological approaches that could be adopted when unusually extended shelf-life is required for UHT milk. However, further studies have been undertaken to evaluate other parameters influencing UHT milk stability, especially the storage at high temperatures such as those occurring in warm regions.

\section{Funding sources}

This research did not receive any specific grant from funding agencies in the public, commercial, or not-for-profit sectors. 


\section{Acknoledgments}

Microscopy observations were carried out at The Advanced Microscopy Facility Platform UNItech NOLIMITS - University of Milan. The authors wish to thank Dr. Miriam Ascagni for her technical support.

\section{References}

Baglinière, F., Tanguy, G., Jardin, J., Matéos, A., Briard, V., Rousseau, F., et al. (2012). Quantitative and qualitative variability of the caseinolytic potential of different strains of Pseudomonas fluorescens: Implications for the stability of casein micelles of UHT milks during their storage. Food Chemistry, 135, 2593-2603.

Cattaneo, S., Masotti, F., Pellegrino, L. (2008). Effects of overprocessing on heat damage of UHT milk. European Food Research \& Technology, 226, 1099-1106.

Cattaneo, S., Stuknyté, M., Pellegrino, L., De Noni, I. (2014). Targeted peptides for the quantitative evaluation of casein plasminolysis in drinking milk. Food Chemistry 155, 179-185.

Chavan, R. S., Chavan, S. R., Khedkar, C. D., \& Jana, A. H. (2011). UHT milk processing and effect of plasmin activity on shelf life: a review. Comprehensive Reviews in Food Science and Food Safety, 10(5), 251-268.

D'Incecco, P., Pellegrino, L., Hogenboom, J. A., Cocconcelli, P. S., \& Bassi, D. (2018). The late blowing defect of hard cheeses: Behaviour of cells and spores of Clostridium tyrobutyricum throughout the cheese manufacturing and ripening. LWT-Food Science and Technology, 87, 134-141. 
Datta, N., \& Deeth, H. C. (2003). Diagnosing the cause of proteolysis in UHT milk. LebensmittelWissenschaft \& Technologie, 36, 173-182.

Deeth H. C., \& Lewis, M. J. (2017). High Temperature Processing of Milk and Milk Products. John Wiley \& Sons, Ltd, Chichester, UK.

De Noni, I., Pellegrino, L., Cattaneo, S., \& Resmini, P. (2007). HPLC of proteose peptones for evaluating ageing of packaged pasteurized milk. International Dairy Journal, 17, 12-19.

Dumay, E., Chevalier-Lucia, D., Picart-Palmade, L., Benzaria, A., Gràcia-Julià, A., \& Blayo, C., (2013). Technological aspects and potential applications of (ultra) high-pressure homogenisation. Trends in Food Science \& Technology, 31(1), 13-26.

Elliott, A. J., Datta, N., Amenu, B., \& Deeth, H. C. (2005). Heat-induced and other chemical changes in commercial UHT milks. Journal of Dairy Research, 72(4), 442-446.

Elwell, M. W., \& Barbano, D. M. (2006). Use of microfiltration to improve fluid milk quality. Journal of Dairy Science, 89, E20-E30.

European Union (2004). Regulation (EC) 882/2004. OJ L 191 of 28.5.2004, pp. 1-52. 
Fernández García, L., Álvarez Blanco, S., \& Riera Rodríguez, F. A. (2013). Microfiltration applied to dairy streams: removal of bacteria. Journal of the Science of Food and Agriculture, 93(2), 187-196.

Gaucher, I., Mollé, D., Gagnaire, V., \& Gaucheron F. (2008). Effects of storage temperature on physico-chemical characteristics of semi-skimmed UHT milk. Food Hydrocolloids, 22, 130143.

Grewal, M. K., Chandrapala, J., Donkor, O., Apostolopoulos, V., \& Vasiljevic, T. (2017). Electrophoretic characterization of protein interactions suggesting limited feasibility of accelerated shelf-life testing of ultra-high temperature milk. Journal of Dairy Science, 100 (1), 76-88.

Hayes, M. G., Fox, P. F., \& Kelly, A. L. (2005). Potential applications of high pressure homogenization in processing of liquid milk. Journal of Dairy Research, 72(1), 25-33.

Hayes, M. G., \& Kelly, A. L. (2003). High pressure homogenization of raw whole bovine milk (a) effects on fat globule size and other properties. Journal of Dairy Research, 70(3), 297-305.

Hardham, J. F., Imison, B. W., \& French, H. M. (2000). Effect of homogenisation and microfluidisation on the extent of fat separation during storage of UHT milk. Australian Journal of Dairy Technology, 55(1), 16-22. 
Hillbrick G.C., McMahon D.J., McManus W.R. (1999). Microstructure of indirectly heated ultrahigh-temperature (UHT) processed milk examined using transmission electron microscopy and immunogold labelling. LWT-Food Science and Technology, 32(8), 486-494.

Hogenboom, J. A., D’Incecco, P., Fuselli, F., \& Pellegrino, L. (2017). Ion-Exchange Chromatographic Method for the Determination of the Free Amino Acid Composition of Cheese and Other Dairy Products: an Inter-Laboratory Validation Study. Food Analytical Methods, 1-12.

Huppertz, T. (2011). Homogenization of milk|: Other types of homogenizer (high-speed mixing, ultrasonics, microfluidizers, membrane emulsification). In Fuquay, J. W., Fox, P. F., \& McSweeney P. L., Encyclopedia of Dairy Sciences. (Volume 2, pp. 761-764). Academic press.

Hussain, H., Truong, T., Bansal, N., \& Bhandari, B. (2016). The effect of manipulating fat globule size on the stability and rheological properties of dairy creams. Food Biophysics, 1(12), 1-10.

Kelly, A. L., \& Foley, J. (1997). Proteolysis and storage stability of UHT milk as influenced by milk plasmin activity, plasmin/ $\beta$-lactoglobulin complexation, plasminogen activation and somatic cell count. International Dairy Journal, 7(6-7), 411-420.

ISO International Organization for Standardization (2004) ISO 18329 - IDF 193:2004 Milk and milk products - determination of Furosine content - ion-pair reverse-phase high performance liquid chromatography method. 
ISO International Organization for Standardization (2007) ISO 11868 - IDF 147:2007 Heat-treated milk-determination of lactulose content. Method using high-performance liquid chromatography (Reference Method).

Lafarge, V., Ogier, J. C., Girard, V., Maladen, V., Leveau, J. Y., Gruss, A., \& Delacroix-Buchet, A. (2004). Raw cow milk bacterial population shifts attributable to refrigeration. Applied and Environmental Microbiology, 70(9), 5644-5650.

Long, Z., Zhao, M., Zhao, Q., Yang, B., \& Liu, L. (2012). Effect of homogenisation and storage time on surface and rheology properties of whipping cream. Food Chemistry, 131(3), 748-753.

López-Fandiño, R., Olano, A., San José, C., \& Ramos, M. (1993). Application of reversed-phase HPLC to the study of proteolysis in UHT milk. Journal of dairy research, 60(1), 111-116.

Lorenzen, P. C., Clawin-Rädecker, I., Einhoff, K., Hammer, P., Hartmann, R., Hoffmann, W., ... \& Devrese, M. (2011). A survey of the quality of extended shelf life (ESL) milk in relation to HTST and UHT milk. International Journal of Dairy Technology, 64(2), 166-178.

Machado S. G., Baglinière F., Marchand S., Van Coillie E., Vanetti M.C.D., De Block J., Heyndrickx M. (2017). The biodiversity of the microbiota producing heat-resistant enzymes responsible for spoilage in processed bovine milk and dairy products. Frontiers in microbiology, 8, article 302, doi 10.3389/fmicb.2017.00302.

Michalski, M. C., Briard, V., \& Michel, F. (2001). Optical parameters of milk fat globules for laser light scattering measurements. Le Lait, 81(6), 787-796. 
Morales, F.J., \& Perez, S.J. (1998). Monitoring of heat-induced proteolysis in milk and milkresembling systems. Journal of Agricultural and Food Chemistry, 46(10), 4391-4397.

O’Mahony, J.A., Fox, P. F., \& Kelly, A. L. (2013). Indigenous enzymes of milk. In Advanced dairy chemistry, volume 1A. Proteins: Basic Aspects. Springer, New York, US. 4th ed., pp. 337-385.

Pellegrino, L., Cattaneo, S., De Noni, I. (2011). Effects of processing on protein quality of milk and milk products. In: Encyclopedia of Dairy Sciences, second edition. Vol. 3. Fuquay JW and Fox PF and Mc Sweeney PHL (eds), Academic Press, San Diego. Pp. 1067-1073.

Pellegrino, L., Rosi, V., D'Incecco, P., Stroppa, A., \& Hogenboom, J. A. (2015). Changes in the soluble nitrogen fraction of milk throughout PDO Grana Padano cheese-making. International Dairy Journal, 47, 128-135.

Picart, L., Thiebaud, M., René, M., Guiraud, J. P., Cheftel, J. C., \& Dumay, E. (2006). Effects of high pressure homogenisation of raw bovine milk on alkaline phosphatase and microbial inactivation. A comparison with continuous short-time thermal treatments. Journal of dairy research, 73(4), 454-463.

Rauh, V. M., Sundgren, A., Bakman, M., Ipsen, R., Paulsson, M., Larsen, L. B., \& Hammershøj, M. (2014). Plasmin activity as a possible cause for age gelation in UHT milk produced by direct steam infusion. International Dairy Journal, 38(2), 199-207. 
Recio, I., de Frutos, M., Olano, A., \& Ramos, M. (1996). Protein changes in stored ultra-hightemperature-treated milks studied by capillary electrophoresis and high-performance liquid chromatography. Journal of agricultural and food chemistry, 44(12), 3955-3959.

Recio I. \& Olieman C., (1996). Determination of denatured serum proteins in the casein fraction of heat-treated milk by capillary zone electrophoresis, Electrophoresis 17, 1228-1233.

Schlender, M., Minke, K., Spiegel, B., \& Schuchmann, H. P. (2015). High-pressure double stage homogenization processes: influences of plant setup on oil droplet size. Chemical Engineering Science, 131, 162-171.

Stoeckel, M., Lidolt, M., Achberger, V., Glück, C., Krewinkel, M., Stressler, T., ... \& Hinrichs, J. (2016a). Growth of Pseudomonas weihenstephanensis, Pseudomonas proteolytica and Pseudomonas sp. in raw milk: Impact of residual heat-stable enzyme activity on stability of UHT milk during shelf-life. International Dairy Journal, 59, 20-28.

Stoeckel, M., Lidolt, M., Stressler, T., Fischer, L., Wenning, M., \& Hinrichs, J. (2016b). Heat stability of indigenous milk plasmin and proteases from Pseudomonas: A challenge in the production of ultra-high temperature milk products. International Dairy Journal, 61, 250-261.

Thiebaud, M., Dumay, E., Picart, L., Guiraud, J. P., \& Cheftel, J. C. (2003). High-pressure homogenisation of raw bovine milk. Effects on fat globule size distribution and microbial inactivation. International Dairy Journal, 13(6), 427-439. 
Verdi, R. J., \& Barbano, D. M. (1991). Properties of Proteases from Milk Somatic Cells and Blood Leukocytes1. Journal of Dairy Science, 74(7), 2077-2081.

Walstra, P., Wouters, J. T., \& Geurts, T. J. (2006). Dairy Science and Technology Second Edition. Food Science and Technology-New York-Marcel Dekker.

Zhang, S., Liu, L., Pang, X., Lu, J., Kong, F., \& Lv, J. (2016). Use of microfiltration to improve quality and shelf life of ultra-high temperature milk. Journal of food Processing and Preservation, 40, 707-714. 
Results

Table 1. Values of heat damage markers measured in the freshly produced UHT and MF-UHT milk samples.

\begin{tabular}{ccccc}
\hline \multicolumn{2}{c}{ Sample } & $\begin{array}{c}\text { Furosine } \\
\left(\mathbf{m g ~ 1 0 0} \mathbf{~}^{-1} \mathbf{g}_{\text { protein }}\right)\end{array}$ & $\begin{array}{c}\text { Lactulose } \\
\left(\mathbf{m g ~ L}^{-1}\right)\end{array}$ & $\begin{array}{c}\text { Soluble a-La } \\
\left(\mathbf{m g ~ L}^{-\mathbf{1}}\right)\end{array}$ \\
\hline \multirow{3}{*}{ UHT } & whole & $205 \pm 6^{\mathrm{a}}$ & $653 \pm 12^{\mathrm{a}}$ & $91 \pm 4^{\mathrm{a}}$ \\
& semi-skimmed & $207 \pm 5^{\mathrm{a}}$ & $661 \pm 9^{\mathrm{a}}$ & $85 \pm 9^{\mathrm{a}}$ \\
& skimmed & $212 \pm 7^{\mathrm{a}}$ & $661 \pm 12^{\mathrm{a}}$ & $87 \pm 9^{\mathrm{a}}$ \\
\multirow{3}{*}{ MF-UHT } & whole & $91 \pm 6^{\mathrm{b}}$ & $247 \pm 5^{\mathrm{b}}$ & $307 \pm 9^{\mathrm{b}}$ \\
& semi-skimmed & $91 \pm 4^{\mathrm{b}}$ & $255 \pm 5^{\mathrm{b}}$ & $303 \pm 9^{\mathrm{b}}$ \\
& skimmed & $102 \pm 5^{\mathrm{b}}$ & $267 \pm 3^{\mathrm{b}}$ & $311 \pm 9^{\mathrm{b}}$ \\
\hline
\end{tabular}

Values are the means of three packages analysed in triplicate \pm the standard deviation. Values within a column with different superscripts are significantly different $(\mathrm{P}<0.05)$. 
Table 2. Occurrence of instability signs assessed by visual evaluation in UHT or MF-UHT milk samples during storage at $20^{\circ} \mathrm{C}$.

\begin{tabular}{|c|c|c|c|c|c|c|c|c|}
\hline \multirow{2}{*}{$\begin{array}{l}\text { Instability } \\
\text { sign }\end{array}$} & \multirow[t]{2}{*}{ Sample } & \multicolumn{7}{|c|}{ Storage (months) } \\
\hline & & 3 & 4 & 6 & 8 & 10 & 11 & 12 \\
\hline cream layer & \multirow{3}{*}{$\begin{array}{l}\text { Whole } \\
\text { UHT }\end{array}$} & - & - & + & + & + & + & + \\
\hline sediment & & - & - & + & + & + & + & + \\
\hline gel particles & & - & - & - & + & + & + & + \\
\hline cream layer & \multirow{3}{*}{$\begin{array}{l}\text { Whole } \\
\text { MF-UHT }\end{array}$} & - & + & + & + & + & + & + \\
\hline sediment & & - & - & - & - & + & + & + \\
\hline gel particles & & - & - & - & - & - & - & - \\
\hline cream layer & \multirow{3}{*}{$\begin{array}{l}\text { Semi - } \\
\text { skimmed } \\
\text { UHT }\end{array}$} & - & - & + & + & + & + & + \\
\hline sediment & & - & - & + & + & + & + & + \\
\hline gel particles & & - & - & - & - & + & + & + \\
\hline cream layer & \multirow{3}{*}{$\begin{array}{l}\text { Semi - } \\
\text { skimmed } \\
\text { MF-UHT }\end{array}$} & - & + & + & + & + & + & + \\
\hline sediment & & - & - & - & - & - & + & + \\
\hline gel particles & & - & - & - & - & - & - & - \\
\hline cream layer & \multirow{3}{*}{$\begin{array}{l}\text { Skimmed } \\
\text { UHT }\end{array}$} & - & - & - & - & - & - & - \\
\hline sediment & & - & - & - & + & + & + & + \\
\hline gel particles & & - & - & + & + & + & $+*$ & + \\
\hline cream layer & \multirow{3}{*}{$\begin{array}{l}\text { Skimmed } \\
\text { MF-UHT }\end{array}$} & - & - & - & - & - & - & - \\
\hline sediment & & - & - & - & - & + & + & + \\
\hline gel particles & & - & - & - & - & - & + & + \\
\hline
\end{tabular}

Presence of individual instability signs was recorded as positive when it was observed in at least two packages out of the three inspected.

* Complete milk gelling in one package out of three. 

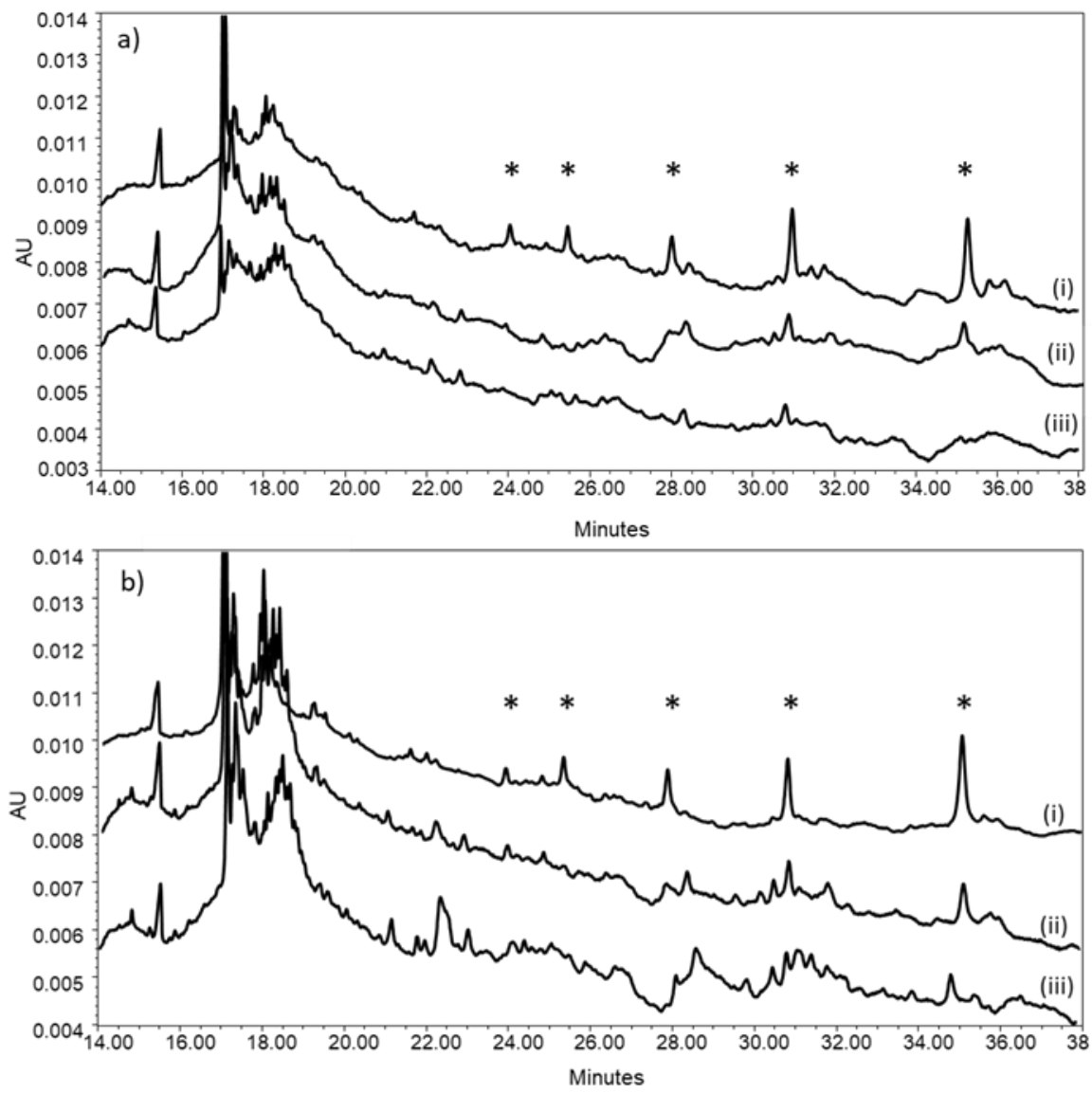

Fig. 1 Capillary zone electrophoresis of proteose peptone in semi-skimmed UHT (a) or MF-UHT (b) milk at 0 (i), 6 (ii) and 12 (iii) months of storage. Asterisks indicate proteose peptone peaks. 

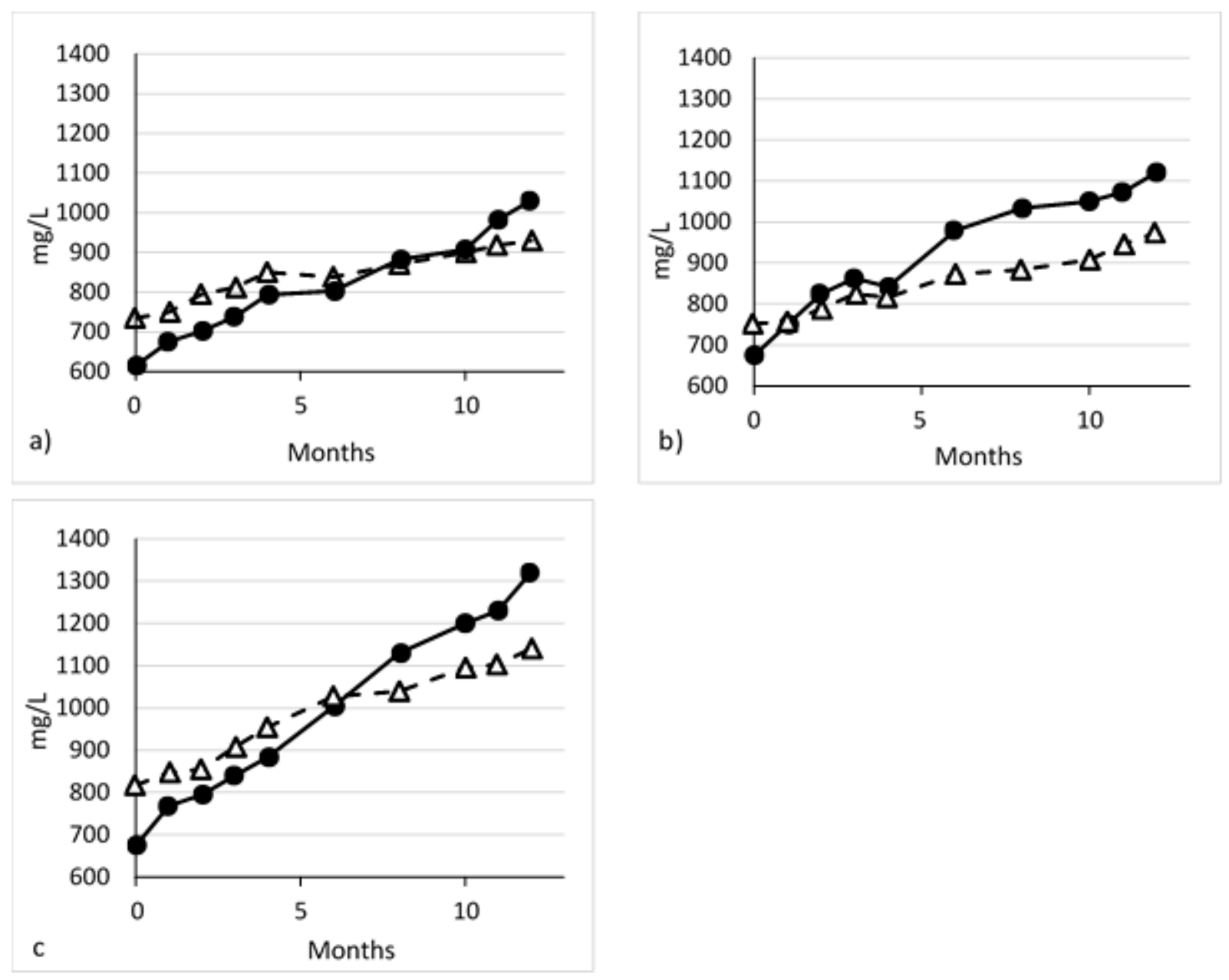

Fig. 2. Small peptides accumulation evaluated by HPLC analysis of whole (a), semi-skimmed (b) and skimmed (c) UHT $(\bullet)$ and MF-UHT $(\Delta)$ milk over a storage period of 12 months. Values are the mean of three packages analysed in triplicate. Relative standard deviation was always $<2.1 \%$. 


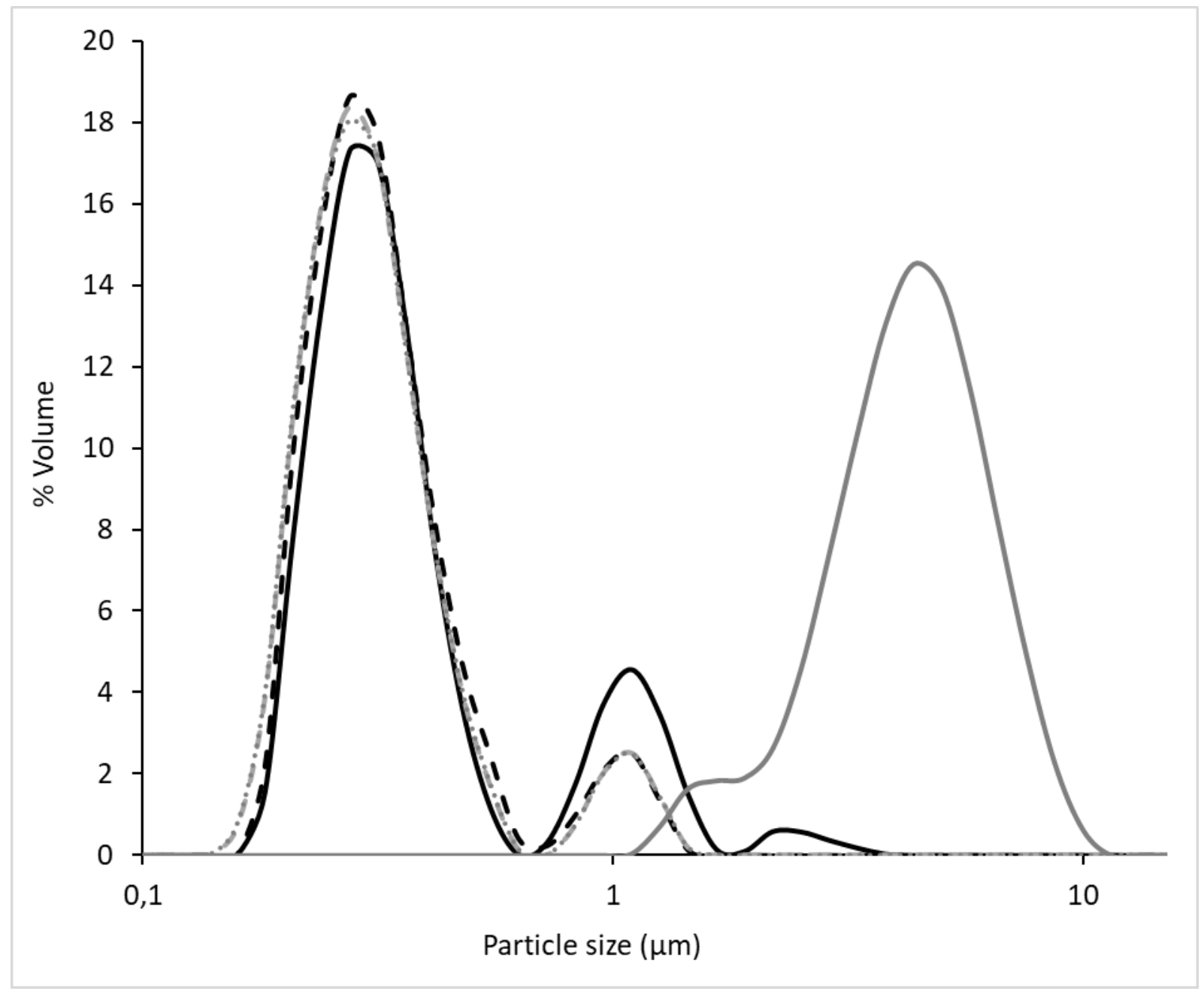

Fig. 3. Light scattering analysis of raw milk (solid gray line) and of once (HOM-1) (solid black line), and twice homogenized milk (HOM-2) (dashed black line) at the beginning of storage, and of HOM-2 after 12 (dashed gray line) and after 18 months of storage (dotted gray line). All samples were mixed at $40{ }^{\circ} \mathrm{C}, 1000 \mathrm{rpm}$ and sonicated for $5 \mathrm{~s}$ prior to $\mathrm{LS}$ measurement. At least three measurements were carried out for each milk sample. 

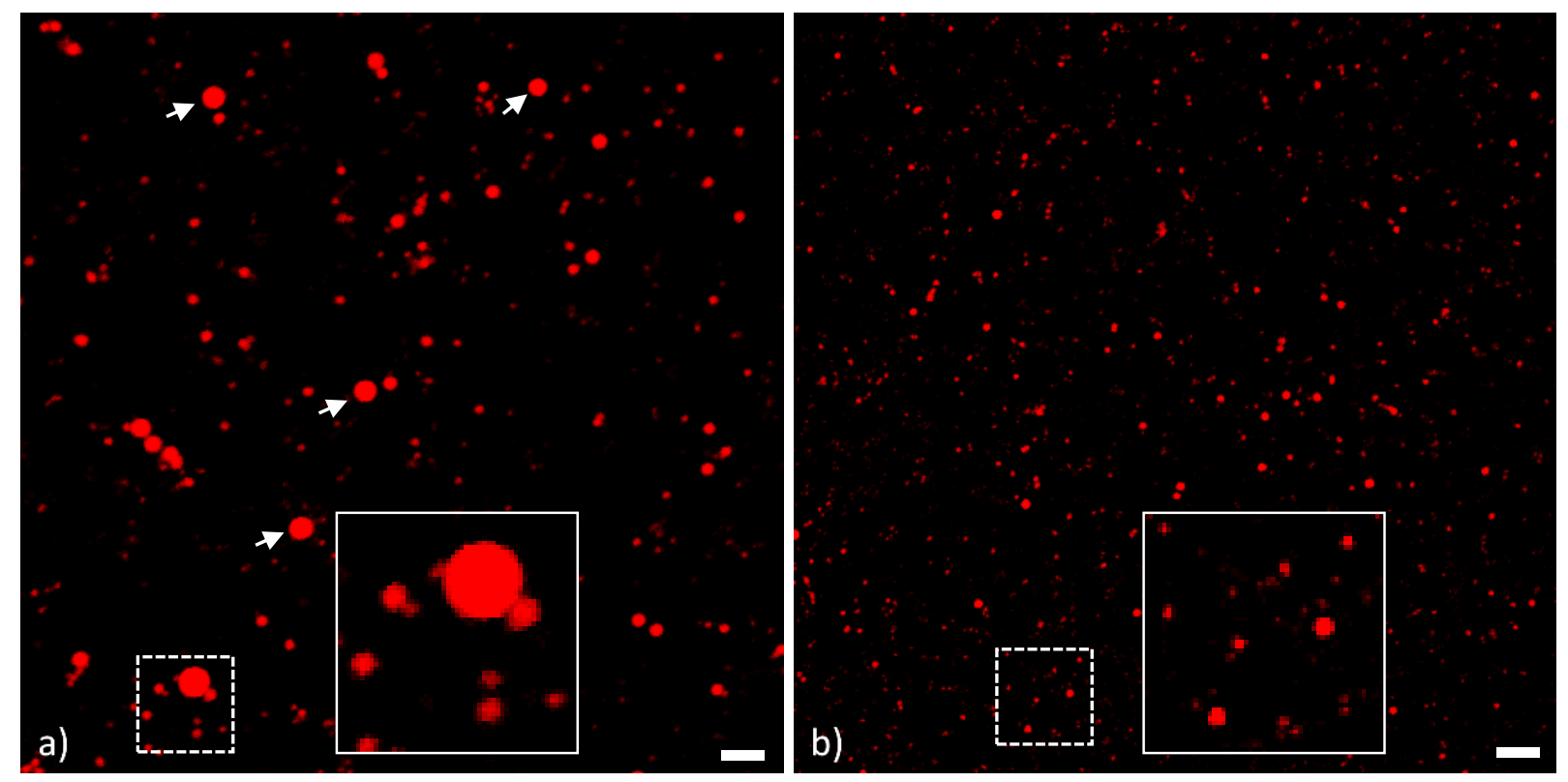

Fig. 4. Microstructure of the fat globules within once (HOM-1, a) or twice (HOM-2, b) homogenized UHT milk. Large fat globules (arrows) are visible only in HOM-1. Images within the dashed frames are enlarged on the right side. The Nile red stained fat globules appear red. The scale bars are $2.5 \mu \mathrm{m}$ in length.
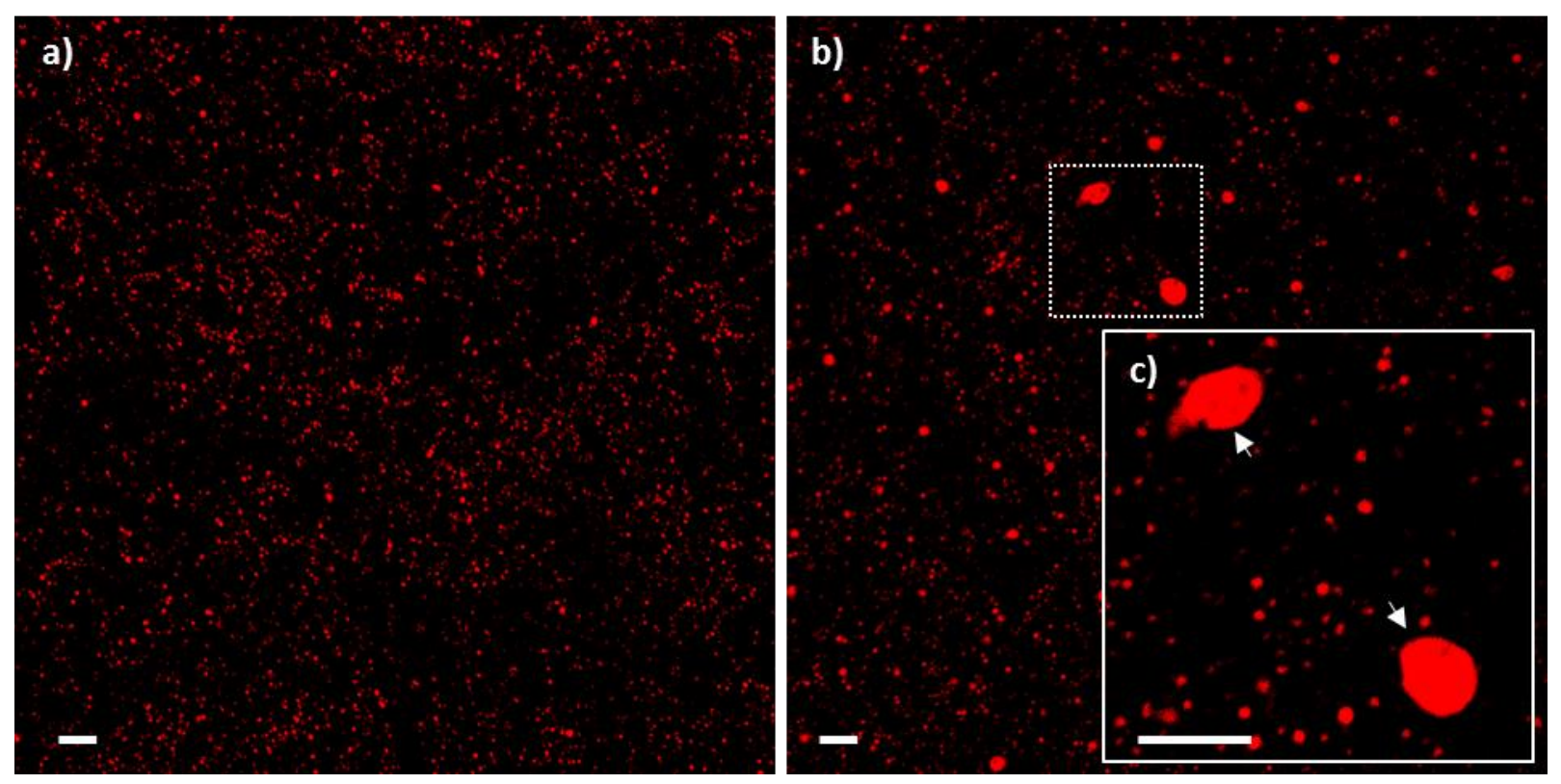

Fig. 5. CLSM images of twice-homogenised UHT milk (HOM-2) sampled at the middle (a) or top

(b) milk layer after 18 months of storage at room temperature. Coalesced fat globules (arrows) are 
visible only in the top layer. Image within the dashed frame is enlarged in panel "c)". The Nile red stained fat globules appear red. The scale bars are $5 \mu \mathrm{m}$ in length.
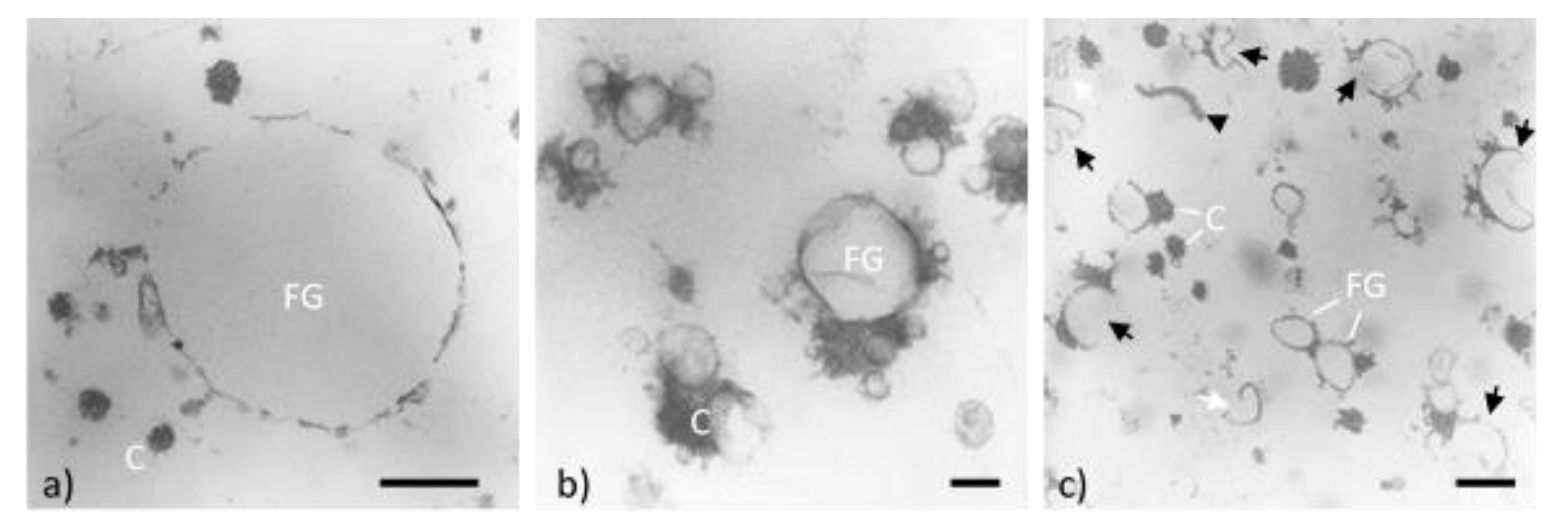

Fig. 6. TEM micrographs of fat globules (FG) in raw milk (a), and in UHT milk homogenized once (HOM-1, b) or twice (HOM-2, c). Only few small casein micelles (C) are stuck to the milk fat globule membrane (MFGM) in raw milk. Numerous damaged fat globules (black arrows) as well as fragments of MFGM (white arrows) are present in HOM-2 sample together with protein fibrils (black arrowhead). Bars are $300 \mathrm{~nm}$ in length in (a) and (c), and $100 \mathrm{~nm}$ in length in (b). 


\section{Supplementary material}
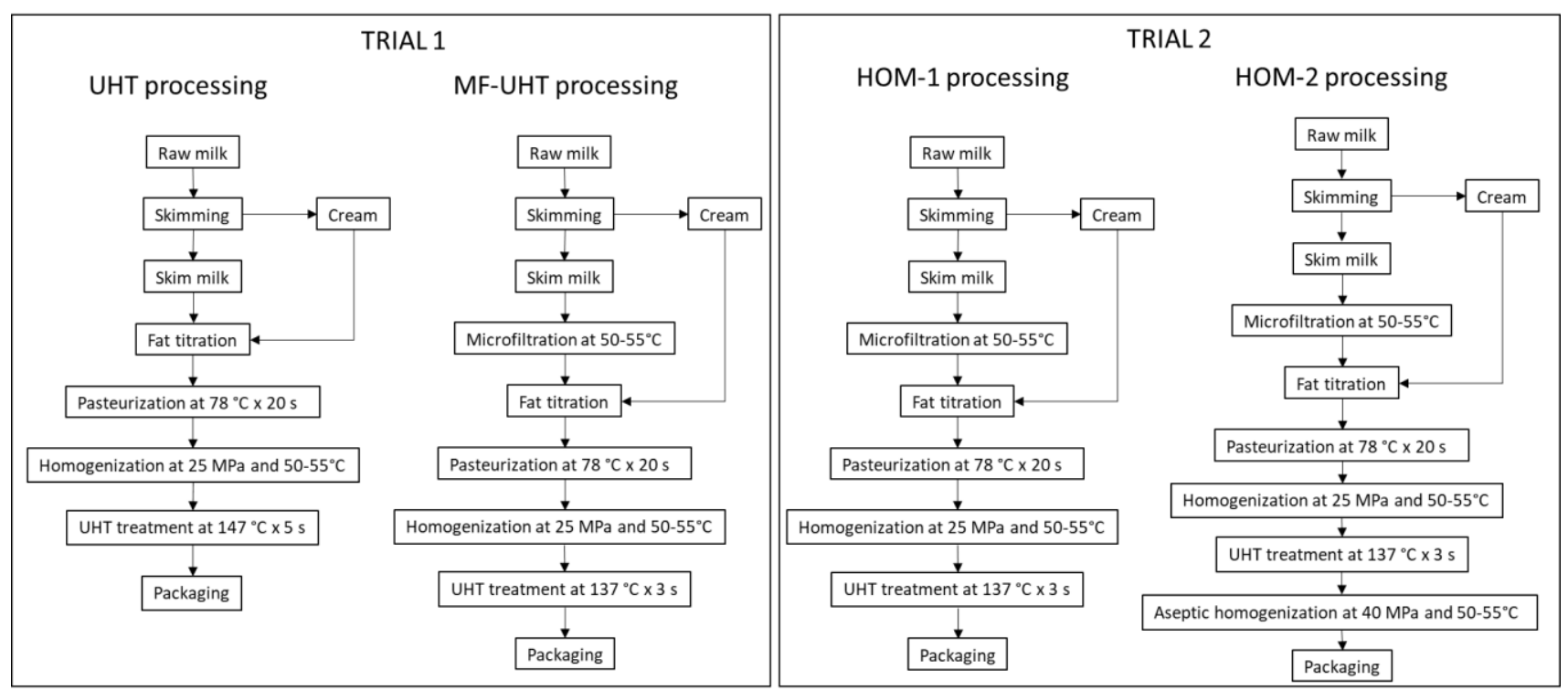

Suppl. Fig. 1. Flow diagrams of processes adopted in "Trial 1" for the comparison of microfiltered UHT milk (MF-UHT) versus the conventional UHT milk; or in "Trial 2" for comparing the double homogenized UHT milk (HOM-2) versus once homogenized (HOM-1) UHT milk.
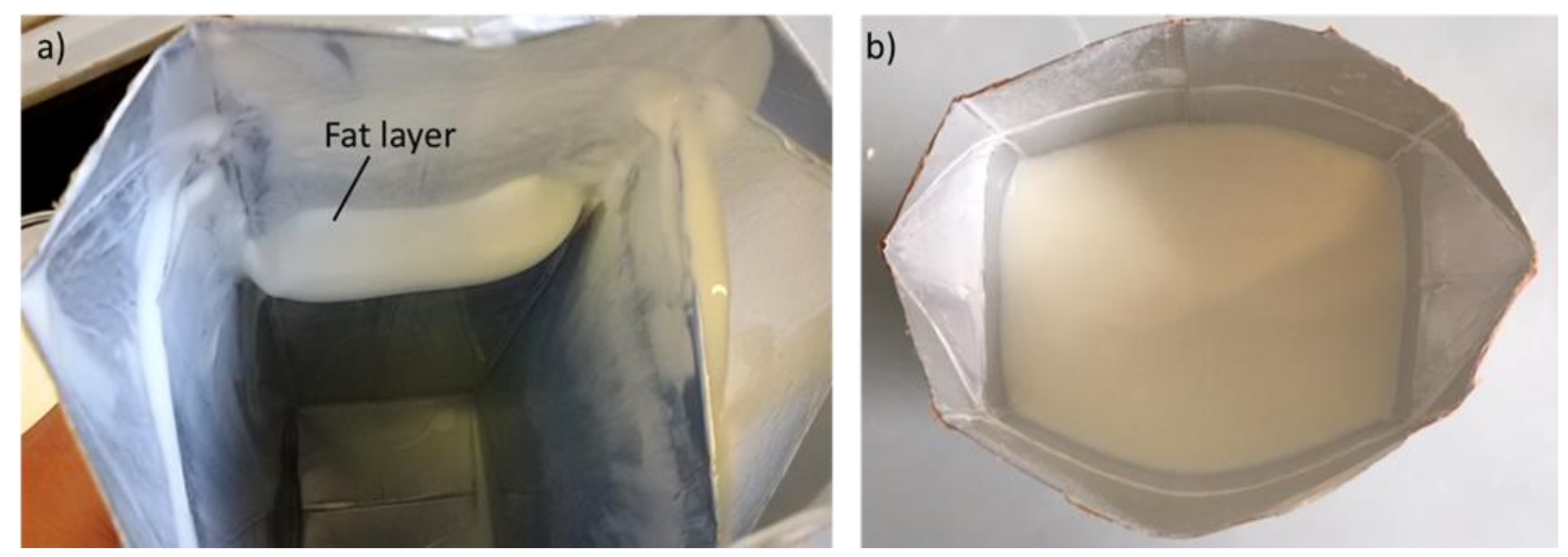

Suppl. Fig. 2. Pictures of HOM-1 (a) and HOM-2 (b) milk packages at opening after 12 months of storage. A fat layer was visible only in the HOM-1 sample after pouring the milk. 